\title{
MEMBENTUK JIWA KEPEMIMPINAN PADA STAF DI YAYASAN PKBM AMARI
}

\author{
${ }^{1}$ Zaki Zainal Arifin, ${ }^{2}$ Rahmayanti, ${ }^{3}$ Annie Rufeidah, \\ ${ }^{4}$ Dyas Mulyani Benazir, ${ }^{5}$ Riri Oktarini \\ Dosen Sekretari Fakultas Ekonomi Universitas Pamulang \\ Email : zakizainalarifin123@gmail.com
}

\begin{abstract}
ABSTRAK
Tujuan kegiatan ini lebih menekankan pada terjadinya hubungan antara personil PKBM serta menciptakan iklim kebersamaan dan saling memiliki yang ditandai dengan rasa kebersamaan dalam bekerja. Dalam kondisi seperti itu akan tercipta hubungan yang harmonis diantara seluruh personil PKBM (Pengelola PKBM, Tutor, Staf Tata Usaha, Warga belajar, dan lain-lain) dan menciptakan lingkungan belajar yang berkualitas dan efektif.

Metode pelaksanaan adalah dengan melakukan survey untuk melihat budaya organisasi dan gaya kepemimpinan di Yayasan PKBM Amari, menyusun bahan ajar untuk presentasi mengenai materi kepemimpinan, melakukan penyuluhan dengan metode tanya jawab dan berbagi pengalaman tentang gaya kepemimpinan yang diterapkan diantara personil PKBM Amari.

Hasil kegiatan ini adalah menciptakan tenaga pengajar yang terampil, komunikatif, dan memiliki jiwa kepemimpinan sehingga terjalin hubungan yang harmonis diantara seluruh personil PKBM (Pengelola PKBM, Tutor, Staf Tata Usaha dan Warga belajar.
\end{abstract}

\section{Kata Kunci: Kepemimpinan dan jiwa kepemimpinan}

\section{PENDAHULUAN}

Pusat Kegiatan Belajar Masyarakat (PKBM) Amari merupakan suatu lembaga yang dibentuk dari, oleh dan untuk masyarakat dalam upaya pemenuhan kebutuhan primer masyarakat dalam bidang pendidikan. PKBM berfungsi sebagai

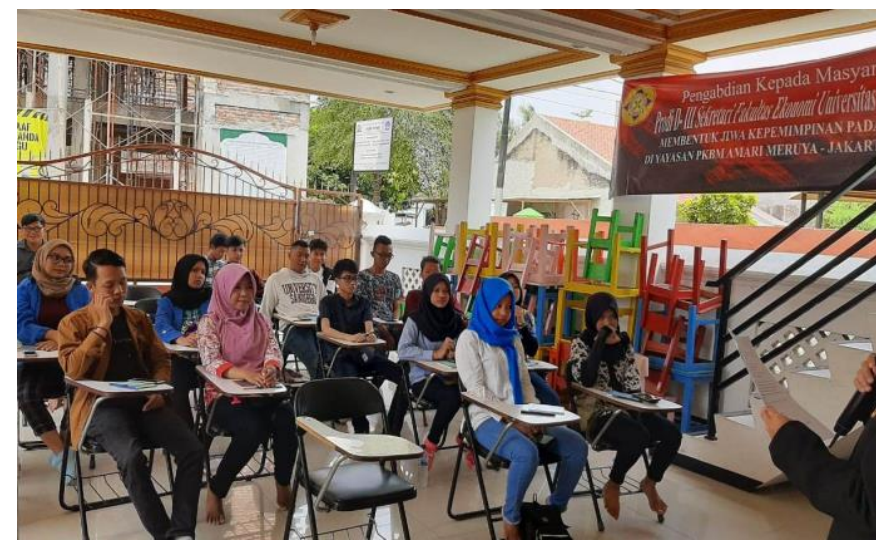
institusi pemberdayaan masyarakat untuk membantu kelompokkelompok masyarakat agar mereka memiliki posisi seimbang dengan kelompok masyarakat lainnya yang lebih mapan dalam kehidupan sosial maupun ekonominya.

menjalankan rangka dan 
menyelengggarakan aktivitas serta kegiatan pendidikan bagi masyarakat, staff PKBM Amari perlu memiliki jiwa kepemimpinan dalam melaksanakan tugasnya sehari-harinya, sehingga kepemimpinan yang ada di PKBM Amari ini lebih menekankan pada terjadinya hubungan antara personil PKBM serta menciptakan iklim kebersamaan dan saling memiliki yang ditandai dengan rasa kebersamaan dalam bekerja sehingga dalam kondisi seperti itu akan tercipta hubungan yang harmonis diantara seluruh personil PKBM (Pengelola PKBM, Tutor, Staf Tata Usaha, Warga belajar, dan lain-lain).

\section{METODE PELAKSANAAN KEGIATAN}

Metode pelaksanaan adalah dengan melakukan survey untuk melihat budaya organisasi dan gaya kepemimpinan di Yayasan PKBM Amari, menyusun bahan ajar untuk presentasi mengenai materi kepemimpinan, melakukan penyuluhan dengan metode tanya jawab dan berbagi pengalaman tentang gaya kepemimpinan yang diterapkan diantara personil PKBM Amari.

Tahap pertama : Tahap persiapan, dimana dosen melakukan survey awal untuk melihat kondisi budaya organisasi di Yayasan PKBM Amari sekaligus langkah pertama untuk ijin menyelenggarakan program pengabdian kepada masyarakat sebagai salah satu tugas dosen dalam mengamalkan tri dharma perguruan tinggi.

Tahap kedua : Dosen pengabdi menyusun bahan dan melakukan presentasi mengenai kepemimpinan disesuaikan dengan kebutuhan di Yayasan PKBM Amari

Tahap terakhir: Dosen pengabdi mengadakan evaluasi atas kegiatan yang telah dilakukan tersebut.

Kegiatan diadakan di Yayasan PKBM Amari Meruya, kelurahan Meruya, Kecamatan Kembangan, Kota Jakarta Barat.

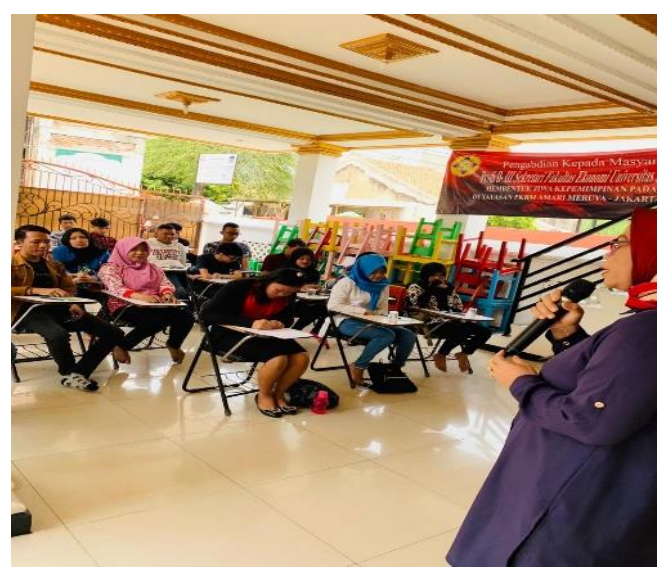

Waktu pelaksanaan selama tiga hari mulai tanggal 17 sampai dengan 18 November 2019.

\section{HASIL DAN PEMBAHASAN}

Pembahasan dan hasil dari kegiatan Pengabdian Kepada Masyarakat ini yaitu antara lain adalah:

a. Jiwa kepemimpinan para staf PKBM Amari dalam menciptakan hubungan yang harmonis diantara seluruh personil PKBM.

Memiliki jiwa kepemimpinan merupakan suatu hal yang sangat penting bagi setiap orang, karena dengan memiliki jiwa kepemimpinan dapat bermanfaat bagi seseorang 
PKBM Amari memiliki beberapa staf dan tenaga pengajar yang aktif dalam memberikan pendidikan kepada murid-muridnya. Dalam kegiatan mengajar jiwa kepemimpinan pada diri para pengajar sangat diperlukan agar para pengajar dapat menjaga suasana saat proses belajar mengajar selalu kondusif.

Begitu pula dengan para staf PKBM Amari juga harus memiliki jiwa kepemimpinan dalam menjalankan pekerjaannya, dengan menerapkan sifat disiplin waktu, fokus dalam bekerja, dan selalu menjaga hubungan baik dengan staf yang lain dan para pegajar.

Peran pemimpin juga sangat dibutuhkan dalam hal ini, seseorang yang dapat memberikan arahan kepada semua staf dan pengajar, seseorang yang mengayomi dan dapat menjadi contoh bagi bawahannya.

Berikut beberapa hal yang dapat meningkatkan jiwa kepemimpinan seseorang:

1) Pengembangan Efektivitas diri

Efektivitas diri dapat dicapai dengan selalu fokus pada tujuan atau cita-cita dan melakukan segala pekerjaan dengan penuh tanggung jawab dan dedikasi tinggi

2) Mengembangkan Kemampuan Persuasif

Melatih kemampuan persuasif sangat diperlukan sebagai seorang pemimpin karena seorang pemimpin harus bisa mempengaruhi bawahan untuk perilaku tertentu, seperti saat memberikan arahan atau ajakan dalam pekerjaan.

3) Mengembangkan Sikap Positif

Seorang pemimpin sebisa mungkin harus selalu memiliki sikap positif terhadap bawahan juga pekerjaannya. Seperti: Berfikir positif, beradaptasi, berpartisipasi, berperan aktif, berbaur, berinteraksi, selalu menjaga keakraban, berterus terang, bekerja sama, saling memahami, menghindari perdebatan dan kata-kata tajam.

b. Cara staf PKBM Amari dalam menciptakan hubungan yang harmonis diantara seluruh personil PKBM

Menciptakan hubungan baik dengan para staf sangat diperlukan dalam menjalin hubungan yang harmonis diantara staf demi terciptanya rasa kepedulian dan kebersamaan.

Ada beberapa cara yang dapat dilakukan untuk menciptakan hubungan yang harmonis diantara personil PKBM Amari:

1) Kebijakan yang Transparan

Menerapkan sikap dan kebijakan terbuka adalah salah satu cara yang baik untuk menjalin hubungan dengan staf di Yayasan PKBM Amari.

2) Berkomunikasi dengan Baik

Komunikasi merupakan hal penting dalam menciptakan hubungan yang harmonis.

3) Luangkan Waktu untuk Seluruh Staf di Yayasan PKBM Amari 
Berusahalah untuk menyediakan waktu dengan seluruh staf untuk menjalin hubungan baik. Contohnya makan siang bersama, ikut merayakan ulang tahun, menjenguk staf yang sakit dan sebagainya.

4) Bersikap Adil Pada Seluruh Staf PKBM.

Hubungan Pemimpin dan staf akan terjalin dengan baik jika pemimpin dapat bersikap adil kepada semua staf tanpa terkecuali.

5) Tetapkan Tujuan yang Jelas dan Masuk Akal Jangan memberikan sesuatu pekerjaan yang tidak akan bisa dilakukan oleh seorang staf.

6) Melibatkan Staf dalam Pengambilan Keputusan Staf akan merasa dihargai dan diakui keberadaannya. Berikan

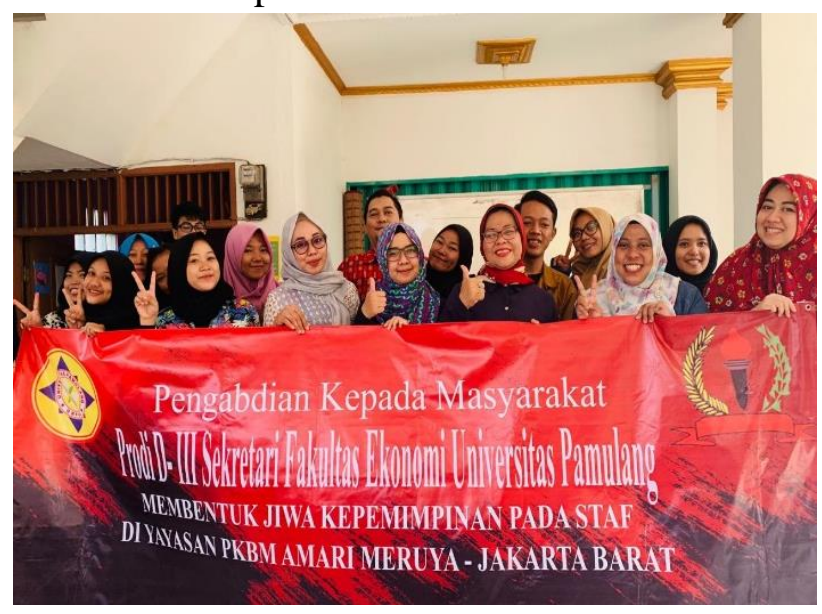
kebebasan staf untuk berpendapat atau memberikan masukan dan ide-ide.

7) Terapkan Peraturan yang Sama Pada Setiap Staf

Sebagai pemimpin sebisa mungkin untuk tidak memanfaatkan status atau kedudukan yang lebih tinggi untuk bersikap sewenang-wenang.

8) Kejujuran Selalu Berikan Hasil yang Terbaik

kejujuran adalah hal utama dalam setiap pekerjaan baik bagi pemimpin atau staf. Ketika pemimpin berbohong kepada staf, maka akan menghancurkan kepercayaan kayawan yang akan berakibat rusaknya hubungan kedua belah pihak.

\section{KESIMPULAN DAN SARAN}

Berdasarkan hasil pelaporan dan pembahasan yang telah diuraikan oleh penulis, maka dapat diambil kesimpulan sebagai berikut:

a. Dalam menumbuhkan jiwa kepemimpinan kepada para staf PKBM merupakan suatu hal yang sangat penting, karena dengan memiliki jiwa kepemimpinan dapat bermanfaat bagi seseorang dalam kegiatan sehari-hari, begitu pula dengan para staf PKBM Amari juga harus memiliki jiwa kepemimpinan dalam menjalankan pekerjaannya, dengan menerapkan sifat disiplin waktu, fokus dalam bekerja, dan selalu menjaga hubungan baik dengan staf yang lain dan para pegajar.

b. Cara staf PKBM Amari dalam menciptakan hubungan yang harmonis di antara seluruh personil PKBM (Pengelola PKBM, Tutor, Staf Tata Usaha dan Warga belajar yaitu kebijakan harus transparan, komunikasi efektif, melibatkan seluruh staf dalam kegiatan PKBM. 
Berdasarkan kesimpulan di atas, maka penulis memberikan saran kepada PKBM Amari untuk dapat memberikan pelatihan kepemimpinan kepada seluruh staf PKBM secara berkelanjutan dan melakukan evaluasi dari setiap kegiatan yang dilakukan agar kedepannya dapat meningkatkan prestasi PKBM Amari.

\section{DAFTAR PUSTAKA}

Assauri, sofjan. 2013. Strategic Management : Sustainable Competitive Advantage. Jakarta : PT RajaGrafindo Persada.

Afriyenti, Mayar dan Fauzan Misra. Kepemimpinan Dalam Akuntansi : Penintegrasian Topik dan Pengalaman Kepemimpinan ke dalam kurikulum Akuntansi. Jurnal WRA, vol 2, No. 2, Oktober 2014.

Baum, Herb. 2004. The Transparent Leader. Jakarta : PT. Bhuana Ilmu Populer.

Benyamin, Alexander. 2014. Kunci Sukses Memimpin Perusahaan. Jakarta: KPG (Kepustakaan Populer Gramedia).

Blanchard Family Partnership dan Margret McBride. 2012. The $4^{\text {th }}$ Secret Of The Minute Manager. Surabaya : PT. Menuju Insan Cemerlang.

Desthiani, Unik. Peranan Gaya Kepemimpinan, Motivasi Dan Disiplin Kerja Terhadap Kinerja Staf. Jurnal Sekretari Universitas Pamulang. Vol 5, No 1 (2014).

http://openjournal.unpam.ac.id/index.php/Sekretaris/article/view/1103

Dewi, Irra Chrisyanti. 2013. Teori Kepemimpinan Managerial (Managership). Jakarta: Prestasi Pustakakarya.

Lensufiie, Tikno. 2000. Leadership untuk Profesional dan Mahasiswa. Jakarta: Erlangga.

Suminar, Ratna. Peningkatan Kompetensi Kepemimpinan Pembelajaran Kepala Sekolah Melalui Pendekatan PAKEM (Metode Studi Kasus pada Diklat Penguatan Kompetensi Kepala Sekolah di PPTK Bisnis dan Pariwisata Tahun 2010). Vol 1, No 2 (2014).

Zainal, Veitzal Rivai, dkk. 2017. Kepemimpinan dan Perilaku Organisasi. Jakarta: PT RajaGrafindo Persada.

http://openjournal.unpam.ac.id/index.php/Sekretaris/article/view/618 